\title{
From forecasts to action - What is needed to make seasonal forecasts useful for South African smallholder farmers?
}

J ulie Wilk, Lotta Andersson, L. P. Graham, J acob Wikner, S. Mokwatlo and B. Petja

The self-archived postprint version of this journal article is available at Linköping University Institutional Repository (DiVA):

http:/ / urn.kb.se/ resolve?urn=urn:nbn:se:liu:diva- 142989

N.B.: When citing this work, cite the original publication.

Wilk, J ., Andersson, L., Graham, L. P., Wikner, J ., Mokwatlo, S., Petja, B., (2017), From forecasts to action - What is needed to make seasonal forecasts useful for South African smallholder farmers?, International J ournal of Disaster Risk Reduction, 25, 202-211.

https:// doi.org/ 10.1016/j.ijdrr.2017.07.002

Original publication available at:

https:// doi.org/ 10.1016/j.ijdrr.2017.07.002

Copyright: Elsevier

http://www.elsevier.com/

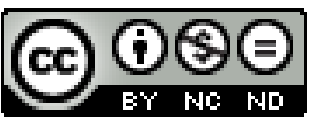




\section{From forecasts to action - what is needed to make seasonal forecasts useful for South}

African smallholder farmers?

Wilk $^{1}$ J., Andersson ${ }^{1,2}$ L., Graham ${ }^{2}$ L.P., Wikner ${ }^{3}$, J.J., Mokwatlo ${ }^{4}$ S. and Petja, B. ${ }^{5,6}$

1. Environmental Science Unit, Department of Thematic Studies, Linköping University, Linköping, Sweden

2. Swedish Meteorological and Hydrological Institute, Sweden

3. Department of Electrical Engineering, Linköping University, Linköping, Sweden

4. Research Directorate, Limpopo Department of Agriculture and Rural Development, Polokwane, South Africa

5. Water Research Commission, Pretoria, South Africa

6. Risk and Vulnerability Science Centre, University of Limpopo, Turfloop, South Africa

\section{Introduction}

Although the long-term effects of climate change will interact with non-climate drivers and stressors to heighten the vulnerability of agricultural systems in many parts of Africa [1], climate variability on the shorter term often has devastating consequences for the food security of agricultural households [2]. In 2016 one of the strongest El Niño events on record drastically affected global weather patterns causing drought conditions that seriously afflicted more than 36 million people from Ethiopia to Zimbabwe. Smallholder farmers, including women who make up around 50 per cent of the agricultural labour force in subSaharan Africa, are especially at risk [3]. Women and youth tend to be more vulnerable to climate-related impacts because they to a higher degree rely on natural resources for livelihoods, are responsible for procuring food, water and fuel, have fewer assets, and meet numerous social, cultural and political barriers [4].

Transformative change is increasingly being recognized as vital to address the overwhelming challenges facing smallholder farmers, including the impact on food and water security from increased drought risks [5]. A key distinction is made between incremental adaptation and deliberate transformation [6]; the former denoting actions to maintain the current system and the latter implying changes in the fundamental attributes of the system so that resilience is enhanced to handle future and even greater challenges [7]. While deliberate transformation has emerged as the new "solution" embraced by 
scientists and activists, it calls for a serious questioning of current assumptions, values, interests and loyalties, and identifying and addressing individual and collective blind spots. Transformational adaptations, proactive or reactive, are expected to be increasingly necessary especially for marginalized or vulnerable groups [8]. In agriculture these could include large-scale shifts from cropped areas to pastoralism [9], organic farming [10] or farm forestry [11]. A transformational approach could also focus on reducing risk and vulnerability [7] that instead of directly responding to climate impacts, involves altering the risk to global development and human security by aiming to change the basic conditions that underlie vulnerability [8].

Seasonal climatological forecasts (SF) have in recent years become an essential part of disaster and risk planning. Early warning systems (EWS), based on forecast information could reduce smallholder farmers risks related to drought and inform decisions and recommendations during the hazardous period. However, without coordinated national drought policies that focus on risk management, EWS, along with impact assessments and drought relief will continue to be part of a reactive, crisis management approach towards drought management [12] [13] and not enable more transformation processes that reduce the vulnerability of smallholder farmers and increase food security.

Recent drought and flood management strategies and systems, such as the United Nations Strategy on Disaster Risk Reduction [13] and the Drought Management Systems currently under development in the European Union [14], reflect a transformational change from disaster management towards a people-centred preventive approach. Historically this transition has been hampered by limited efforts to recognize and address drought risks including the contextual factors that underlie the vulnerability of people and agricultural systems [15]. The latest UN framework on disaster reduction [13] supports deliberate transformation by highlighting the importance of reducing vulnerability by tackling underlying disaster risk drivers e.g. poverty and inequality, climate change and variability, poor land management and non-risk-informed policies, through dedicated action.

In South Africa, the Agricultural Disaster Risk Management Plan (ADRMP) and the Agricultural Drought Management Plan (ADMP) were passed in 2008 based on the framework of the Disaster Management Act (DMA) No. 57 of 2002. These plans marked a shift towards more proactive risk management from previous drought management strategies, which mainly relied on reactive short-term responses such as post-drought relief 
and restrictions on water supply during low-flow periods. Consequently, more recent efforts have recognized a more proactive approach to managing drought as linked to agricultural production planning and management [16]. While the South African government has provided disaster relief for many years, the assistance has been found to focus on meeting farmers' immediate needs without contributing to their increased resilience to future hazards [17]. It also suffers from poor timeliness, ineffectiveness and poor coordination [18]. Studies of farmers' perceptions have pointed out poor logistical solutions around transportation and feed storage [17] and a poor collaboration and coordination of government departments at national and provincial level [19]. Other studies have suggested that relief agencies could speed up subsidies and crisis responses by identifying which tasks can be done in advance [20] for example using SFs to improve the timing of seed delivery [21]. Use of SFs as part disaster management decisions and actions has been suggested as a way to link the crisis calendar to the decision calendar [22].

If smallholder farmers are to make timely decisions, increase yields and avert disastrous situations, they must be able to make use of forecast information to prepare for and mitigate negative outcomes. The inclusion of information on hydrological impacts, recommendations and guidance on possible actions can increase forecast usefulness [23]. Vermeulen et al. [24] pointed out that a common mismatch between smallholder farmers' needs and the accuracy, format, scale and content of early warnings. In Zimbabwe farmers who made changes to their farming practices based on SFs ( $50 \%$ altered the time of planting and $40 \%$ planted different crop varieties) reported $10 \%$ increased harvests (averaged for the two year study) as compared to farmers that did not act on the information [25]. Yet to effectively use SFs and early warnings, farmers must also have the capacity, resources and sufficient lead-time to respond [26] [27]. Previous studies in Africa have provided little evidence that forecasts alone, without other interventions such as seed distribution or increased access to credit or lower prices for fertilizers, will lead to improved harvests [25] [28].

In this paper we explore barriers that hinder the use of SFs for drought in risk management, as well as ways that would allow SF information to become more useful to smallholder farmers. The study took place in the Limpopo Province, South Africa and is based on dialogues with representatives of Extension and Advisory Services and Disaster Management Services of the Limpopo Department of Agriculture and Rural Development 
(LDARD). Assessments were made at the national, regional, provincial, district municipality, service centre ${ }^{1}$ and community levels.

We organize and discuss our material according to three interacting "spheres" of transformation - the practical, political and personal - that illustrate distinct yet related arenas or entry points where transformational adaptation processes may be realized to support climate-resilient pathways for sustainable development [8]. The personal sphere includes beliefs, values, worldviews and paradigms; the political, systems, institutions and structures and the practical, behaviour and technical responses. The recognition that technical and behavioural changes essential to transformational adaptation are embedded in larger systems and structures, shifts the narrow view of addressing adaptation through technical systems to a more holistic one that also recognizes the importance of social and political dimensions.

We aim to specifically answer:

- What are the barriers that limit the use of SFs by smallholder farmers and policymakers?

- Which potential changes in the practical, political and personal spheres could foster the use of SFs in risk management?

\section{Methods and Study Area}

The empirical material in this study was collected in interviews and participatory workshops undertaken in a larger project "Local early warning systems for drought: Can they increase community resilience?" undertaken between June 2013 and October 2015. The project encompassed two rainy seasons, 2013-2014 (forecasted as wetter than normal) and 20142015 (forecasted as drier than normal).

\subsection{Participatory workshops}

In the project, a pilot for a participatory EWS for local drought monitoring and forecasts was developed and evaluated by two farming communities, Lambani (Vhembe district municipality) and Mokwakwaila (Mopani district municipality) in Limpopo Province. The EWS included seasonal climatological forecasts coupled to a hydrological model, indigenous

\footnotetext{
${ }^{1}$ Services centers are part of the organization scheme of the LDARD Extension and Advisory Services lying under the local municipality level.
} 
knowledge (i.e. signs in nature that indicate drier or wetter conditions) and wireless sensors for monitoring rainfall and soil moisture [29]. Several workshops were held in the communities to design and assess the system. Workshops identified and assessed farmers' actual and potential responses to SFs, how farmers do or would respond to SF information as well as how they observed and used signs in nature to forecast conditions of the coming season. In addition, seven workshops were held with invited LDARD staff from Disaster Management Services (provincial head office and district offices) and Extension and Advisory Services responsible for Mokwakwaila and Lambani communities, the Agricultural Research Council, University of Limpopo, University of Venda, and the Association for Water and Rural Development (NGO). The workshops presented the progress of the project and contained participatory exercises to collect information on: i) availability, communication and use of SFs by LDARD and smallholder farmers; ii) prevalence, communication and use of signs in nature by farmers; iii) types of hydrological information e.g. rainfall, soil moisture, river discharge that is most useful for farmers, including critical levels of hydrological variables and iv) responses by farmers to cope with wet and dry seasons. Two workshops were held in June 2015 with staff from Extension and Advisory Services and Disaster Management Services in the service centres of Letaba Municipality and Mopani District Municipality (29 participants) and Thulamela Local and Vhembe District Municipality (40 participants) respectively. We assessed current limitations and opportunities for change in the communication of existing SF information and their increased potential in extension work with smallholder farming communities. Notes were taken at the workshops and the content coded, categorized and analyzed according to workshop themes.

\subsection{Interviews}

Ten interviews were held with staff of LDARD's Disaster Management Services at provincial and district municipality level and Extension and Advisory Services at service centre level with responsibility for the Lambani and Mokwakwaila communities. The interviews were open and semi-structured allowing opportunities to expand on issues of interest. All interviews were conducted in English. The responses were content coded and categorized according to identified themes. Questions included: what current SFs are available; how does LDARD receive and make use of SFs; what is useful and problematic about the way information is presented in (e.g. content, format, timing); what changes would be 
recommended; what are the current channels for dissemination; what channels of dissemination are recommended; how are uncertainties and probabilities communicated; what problems with dissemination are identified; how do smallholder farmers presently use SFs; what groups of smallholder farmers (age, livestock, irrigation, dryland, emerging ${ }^{2}$, etc.) can best make use of the information; and what hinders smallholder farmers from using SFs.

\subsection{Climate and its impacts}

Limpopo province is characterized by high climatic variability and is one of the driest regions in South Africa. It is prone to flood events and severe droughts and experiences high intraseasonal variability during the rainy season (December to February). The Luvuvhu and Letaba sub-catchments of the Limpopo River Basin areas have mean annual rainfall of 600 $\mathrm{mm}$ and mean annual potential evaporation of $1670 \mathrm{~mm}$. Rainfall varies significantly between years and occurs on a few isolated rain days seldom exceeding 50 rain days per year [30]. The Luvuvhu sub-catchment, where the Lambani community is situated, has slightly higher rainfall and evaporation than the Letaba sub-catchment, where Mokwakwaila is located. Drought is a recurring problem in both communities. Lower than normal rainfall results in decreases in agricultural activities, livestock losses, shortages of drinking water, low yields and shortage of seeds for planting [31]. In addition, the Luvuvhu area also suffers from recurrent high intensity rainfall events and flash floods that cause soil erosion, damage to water and road infrastructure and crop losses. High climate variability in both subcatchments makes planning for agricultural production difficult for smallholder farmers.

\subsection{Study communities}

Lambani community members belong to the Venda ethnic group and those in Mokwakwaila to Tsonga/Northern Sotho/Pedi groups. Both communities contain approximately 525 households each [32]. Smallholder farmers in both areas make up the majority of the farming community. They practice dryland agriculture growing predominantly maize and some vegetables for their own consumption, with any surplus sold or loaned to neighbours or relatives. The most common adaptation strategies for dealing with high climatic variability are planting early maturing or drought tolerant crops, crop and livestock diversification,

\footnotetext{
${ }^{2}$ Emerging farmers are previously disadvantaged farmers now that have their own land and are starting out in commercial farming.
} 
culling livestock and storing food [31]. The common farm size is one hectare or less. Most families obtain their household water from communal outdoor sources. A few households own small numbers of cattle, sheep or goats. Most farmers are over 60 years of age and receive government pensions that support households when agricultural yields are low. Many younger people have moved to urban areas or live with and rely on the pensions of their older relatives in rural communities without being actively involved in the farming activities.

\subsection{Disaster management for drought}

Specific responsibilities and tasks related to disaster management for drought are held at different LDARD administrative levels, which we briefly describe in this section. The actual division of responsibilities at different LDARD levels is not always clear, particularly regarding to top-down information dissemination. Bottom-up flows of information are mainly reactive, e.g. lower administrative levels report drought-related events to the provincial level after they have occurred (Fig. 1).
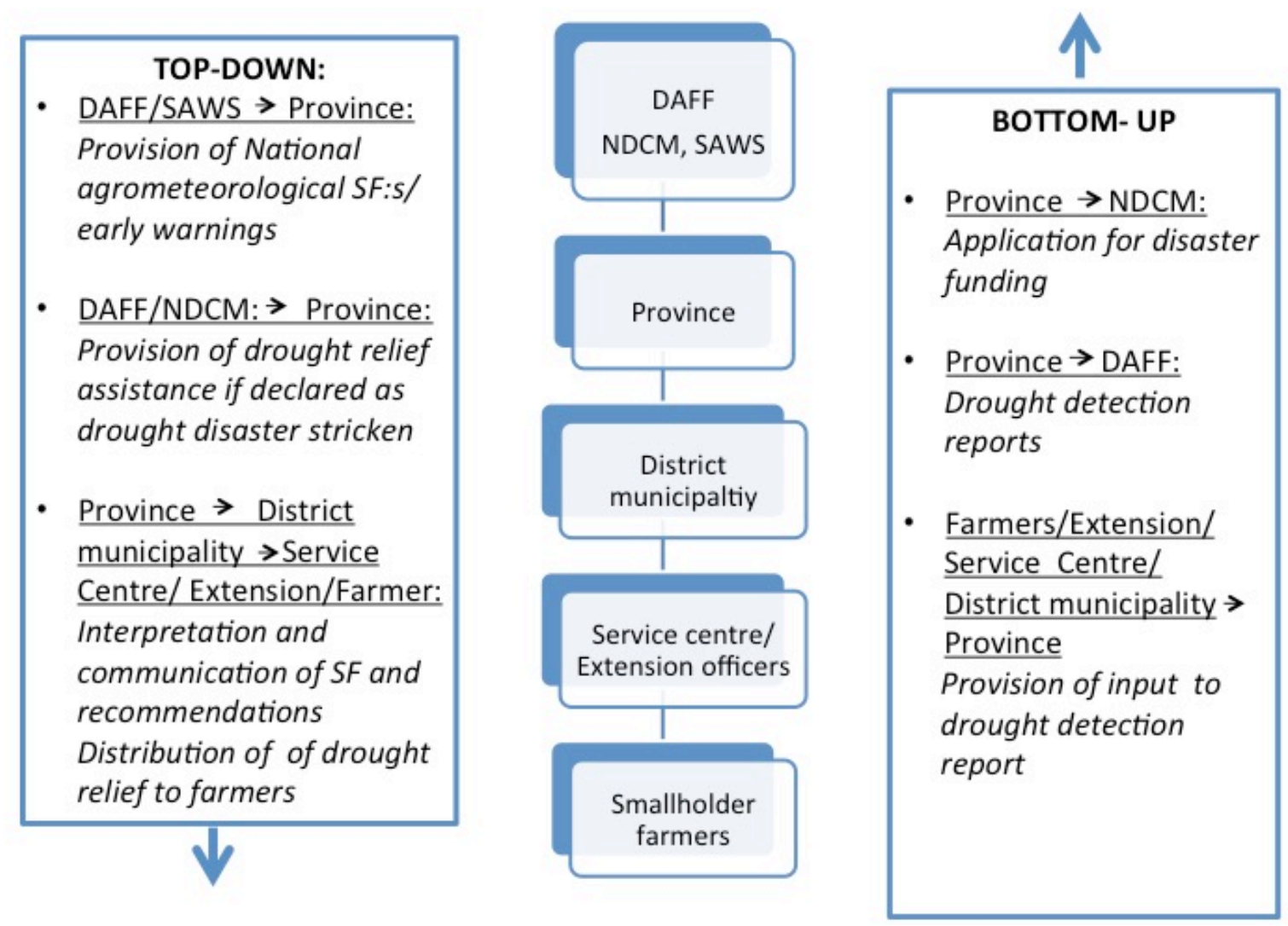
Figure 1. Top-down flow of SFs including recommendations of actions and drought relief. Bottom-up flow consists of post-event drought declarations and applications for disaster relief.

At national level, the Directorate of Climate Change and Disaster Management within the Department of Agriculture, Forestry and Fisheries (DAFF) develop and provide a National policy framework and national plan for drought disaster management for their sectors. These include early warnings from the South African Weather Service (SAWS) with national agro-meteorological SFs that are delivered approximately once a month. They also guide the coordination and facilitation of the post-drought disaster recovery process between the National Disaster Management Centre (NDMC) and provincial LDARD Disaster Management Services, including declarations and funding requests from drought stricken provinces. The provincial departments compile reports including drought declarations for their province.

At district municipality level, LDARD Disaster Management Services is responsible for disseminating SFs and early warnings to farmers, developing drought mitigation strategies and guidelines on implementation of approved strategies, ensuring that farming communities implement risk reduction measures, performing drought assessments and implementing disaster relief to affected farming communities. The office is also responsible for regularly disseminating SF to extension officers based at the local municipalities and service centres and even directly to farmers at farmer information days or through short message services (SMS) if they have requested this service and the farmers understand English. No farmers in Lambani and Mokwakwaila communities were receiving SFs on their cellular phones during this study.

At local municipality and service centre levels, staff of LDARD Extension and Advisory Services, some of which are also appointed as Early Warning officers with specific duties related to this function in their job descriptions, interpret and communicate SF information to smallholder farmers as well as recommended responses.

\section{Limitations related to seasonal forecasts}

This section describes the SFs received from national level, the main limitations in the forecast information and how it is perceived by LDARD staff. In Fig. 1 this information is arranged according to the three interacting transformation spheres- practical, political and 
personal at different administrative levels, national, provincial, district municipality, service centre and community.

\section{Barriers that limit understanding of seasonal forecasts}

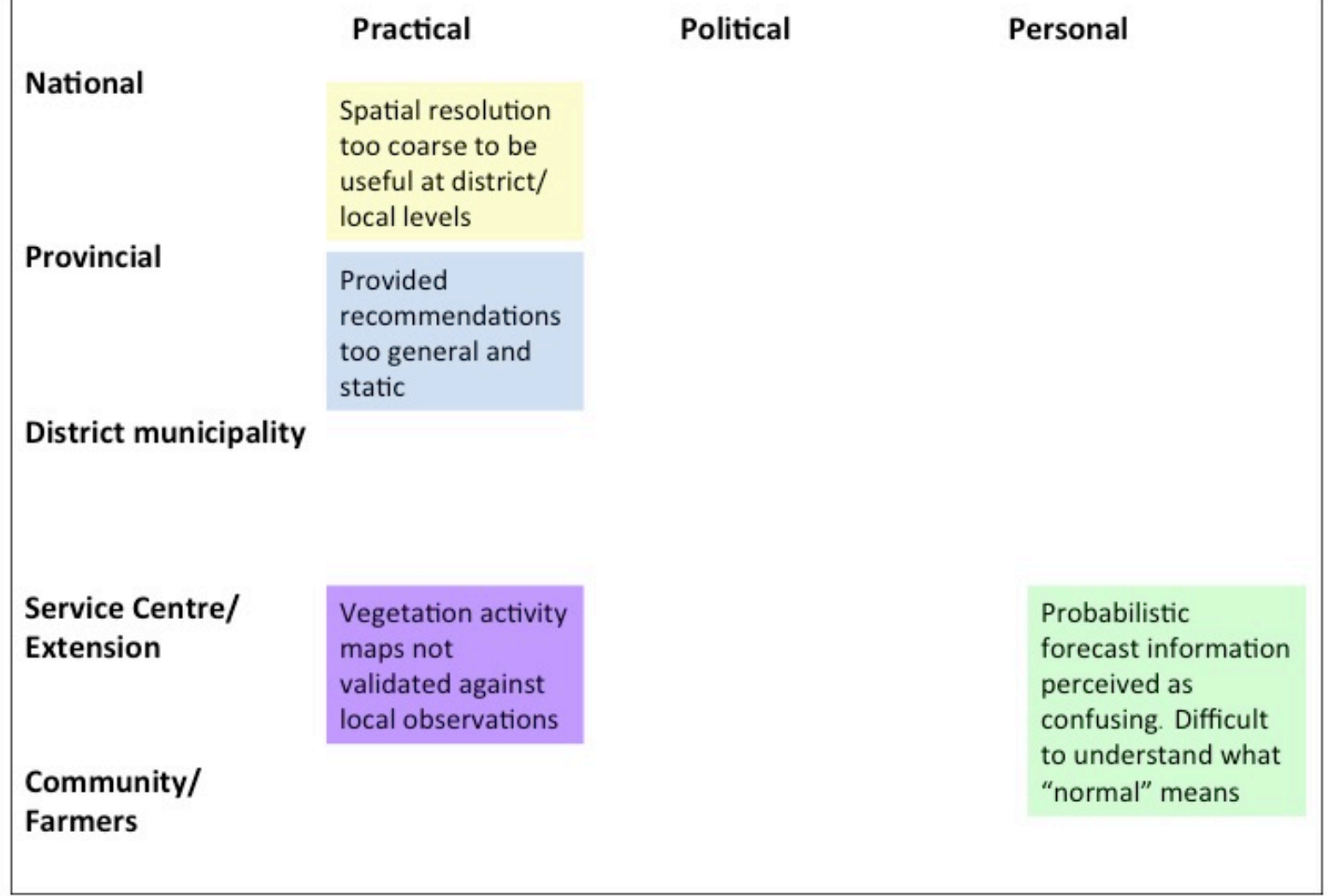

Fig. 2. Identified barriers that limit the usefulness of seasonal forecasts (SF) related to accuracy (purple), format (green), scale (yellow) and content (blue) at the national, provincial, district, service centre and community levels of the LDARD.

\subsection{The seasonal forecasts}

The SFs received from the national level are probabilistic, e.g., they are based on the probability that below-, above- or normal conditions will occur. They are created from seasonal climatological ensemble forecasts that are performed over a period covering the coming five months. Using an ensemble forecast means that several simulations of a forecast model have been made for the same period (usually 10 years or more), but with slightly different initial conditions. This leads to slightly different forecasts from each simulation. The summarized statistics from the different simulations are presented in the SF, where they are compared to long-term mean values produced by the same forecast model. They are summarized as three month periods lagged by one month, such as September- 
October-November (SON), October-November-December (OND) and November-DecemberJanuary (NDJ).

Maps display forecasts of rainfall, maximum and minimum temperature at a scale of $1: 200,000$ with information in grids of $1000 \times 1000 \mathrm{~m}$. They show the probabilities for abovenormal and below-normal conditions to occur as compared to the long-term mean of historical records. For each forecast map of a three-month period, a probability percentage is given from $0 \%$ to $50 \%$. The probabilities indicate the forecasts' direction and the amount of confidence in them. The maps are accompanied by short texts in English that summarize the displayed information. It is possible for the same location to both have an indication of above- and below-normal conditions for the same period. Although one of the signals should dominate, conflicting information is sometimes displayed. In addition, a NDVI (normalized difference vegetation index) difference map shows vegetation activity for the current month compared to the long-term mean (based on 14 years of historical data) with seven levels ranging from below- to above-normal.

SFs are accompanied by suggested strategies for rainfed crop productions, irrigated farming, domestic and home garden water use, livestock farming, grazing management and prevention of veld fires. They are general and describe a number of recommended activities that are not specifically linked to the forecasted conditions of the coming months. A text explains that the provided advisories are broad guidelines and should be further interpreted with consideration to the local aspects of each region such as soil types, cultural preferences and farming systems.

\subsection{Barriers related to the scale, content, form and accuracy of the forecasts}

Limitations of the perceived usefulness of forecasts can be related to the scale, content, form and accuracy [24]. The SF maps have a very coarse spatial resolution that makes the extraction of information for site-specific locations difficult. Although the SF texts advise that "the provinces should further simplify, downscale and package the information according to their language preference", study participants at all administrative levels pointed out that the provincial Disaster Management Services sends out the forecasts received from national level without any additional interpretation for Limpopo Province, or adjustment of suggested strategies for farmers. Since the strategies are static and not site-specific, 
extension officers perceived them to be not sufficiently clear to guide farmers in accordance with forecasted conditions.

Some extension officers said that they do not fully understand what SFs are as it is not clearly described in the SFs texts how they are created. While the existence of uncertainty in the forecasts seemed to be understood and accepted by most extension officers in both districts, there were difficulties for some to understand the provided probabilistic information. Some officers added that they lacked an explanation of what "normal" refers to. They considered the maps and accompanying texts to be unclear since they sometimes give conflicting information (indicating both below- and above-normal conditions at the same time).

One extension officer remarked that the NDVI difference maps showing vegetation activity are not validated against observations so they do not necessarily correspond with actual ground conditions. While some respondents said that they do pass on information about emerging drought conditions to higher administrative levels, the chain of communication is long: from community, extension officer, supervisor, manager, senior manager (district) to provincial level (Fig. 1). Other officers stated that they do not know of any channels in which to pass on such information.

\section{Limitations related to the dissemination and understanding of seasonal forecasts}

Limitations related to the dissemination of SFs are discussed below and arranged according to the practical, political and personal spheres at the LDARD administrative levels where they occur (Fig. 3). 


\section{Barriers that limit dissemination of seasonal forecasts}

\begin{tabular}{|c|c|c|c|}
\hline & Practical & Political & Personal \\
\hline $\begin{array}{l}\text { Provincial } \\
\text { District } \\
\text { municipality }\end{array}$ & $\begin{array}{l}\text { SF mainly sent via } \\
\text { LDA email } \\
\text { addresses which } \\
\text { often do not work } \\
\text { Limited follow up if } \\
\text { extension officers } \\
\text { have received and } \\
\text { understood the SF } \\
\text { information }\end{array}$ & $\begin{array}{l}\text { Bottlenecks due } \\
\text { to lengthy way of } \\
\text { SF } \\
\text { communication } \\
\text { from provincial to } \\
\text { community level }\end{array}$ & \\
\hline $\begin{array}{l}\text { Service Centre/ } \\
\text { Extension }\end{array}$ & $\begin{array}{l}\text { Lack of laptops and } \\
\text { access to Internet } \\
\text { - difficult to view } \\
\text { SF maps on cellular } \\
\text { phones }\end{array}$ & $\begin{array}{l}\text { Little time to } \\
\text { disseminate SF } \\
\text { aside from } \\
\text { regular tasks } \\
\text { Farmers can only } \\
\text { access SF } \\
\text { information in } \\
\text { local languages } \\
\text { via extension } \\
\text { staff }\end{array}$ & $\begin{array}{l}\text { Not all } \\
\text { extension staff } \\
\text { read or } \\
\text { under- } \\
\text { stand SFs }\end{array}$ \\
\hline
\end{tabular}

Figure 3. Identified barriers that limit the dissemination and understanding of seasonal forecast (SF) information at the provincial, district municipality, service centre and community levels of the LDARD.

\subsection{The communication channel}

The chain of communication to disseminate SFs from provincial to community levels is lengthy, so there are many risks for bottlenecks and delays (Fig. 1). Employees at the provincial level relate that when they have received the latest SF from the national level, Disaster Management Services staff circulates it to all LDARD departmental offices including district municipality Disaster Management and Extension and Advisory Services at the same time. This is done primarily through departmental email, which is regulated by the Departmental Communication division. After this study ended, the provincial office began to also disseminate SFs to extension officers that had registered their private email addresses but it is unclear to what degree officers have been made aware of this option. A district municipality Disaster Management Coordinator pointed out that SFs are also distributed to all extension officers through group SMS to LDARD cellular phones. Some extension officers 
pointed out that the district Disaster Management Coordinators do not follow-up whether they at service centre level have received or understood the SFs. Extension officers interpret and simplify the information and communicate it to farmers in their local languages. SFs are occasionally disseminated on local radio shows but radio slots are expensive and are normally only used when there is an available budget.

\subsection{Computers and Internet connections}

Informants at all administrative levels reported that the LDARD email system often suffers technical difficulties, for long periods of time, which hinders the timely spread of information. At the workshops with extension officers, $57 \%$ in Letaba Local municipality and 95\% in Thulamela Local and Vhembe district municipalities said that they do not receive SFs. Some of the extension officers indicated that a lack of departmental laptops (for those that do not have private laptops), irregular access to Internet or weak Wi-Fi coverage hampered their receipt of SFs. One officer, who did not have access to a laptop, expressed how difficult it was to see and understand the forecast and interpret information on the small maps, on a cellular phone. A district municipality Disaster Management Coordinator pointed out that all extension officers have access to stationary computers at their service centres to check their mails, provided they have access to Internet connections though the LDARD server.

\subsection{Time}

A district Disaster Management Coordinator said that extension officers are not only engaged with disaster management but many other duties, so it can be difficult for them to prioritize the communication of SF information to farmers. Many extension officers agreed pointing out that they have little time to call additional meetings with farmers to deliver forecast information but they do try to incorporate SF information into the agendas of regularly scheduled farmers' meetings.

\section{Limitations related to actions based on seasonal forecasts}

In this section, existing barriers that limit actions among smallholder farmers are described. They are arranged according to the practical, political and personal spheres at the LDARD administrative levels where they occur (Fig. 4). 


\section{Barriers that limit actions based on seasonal forecast information}

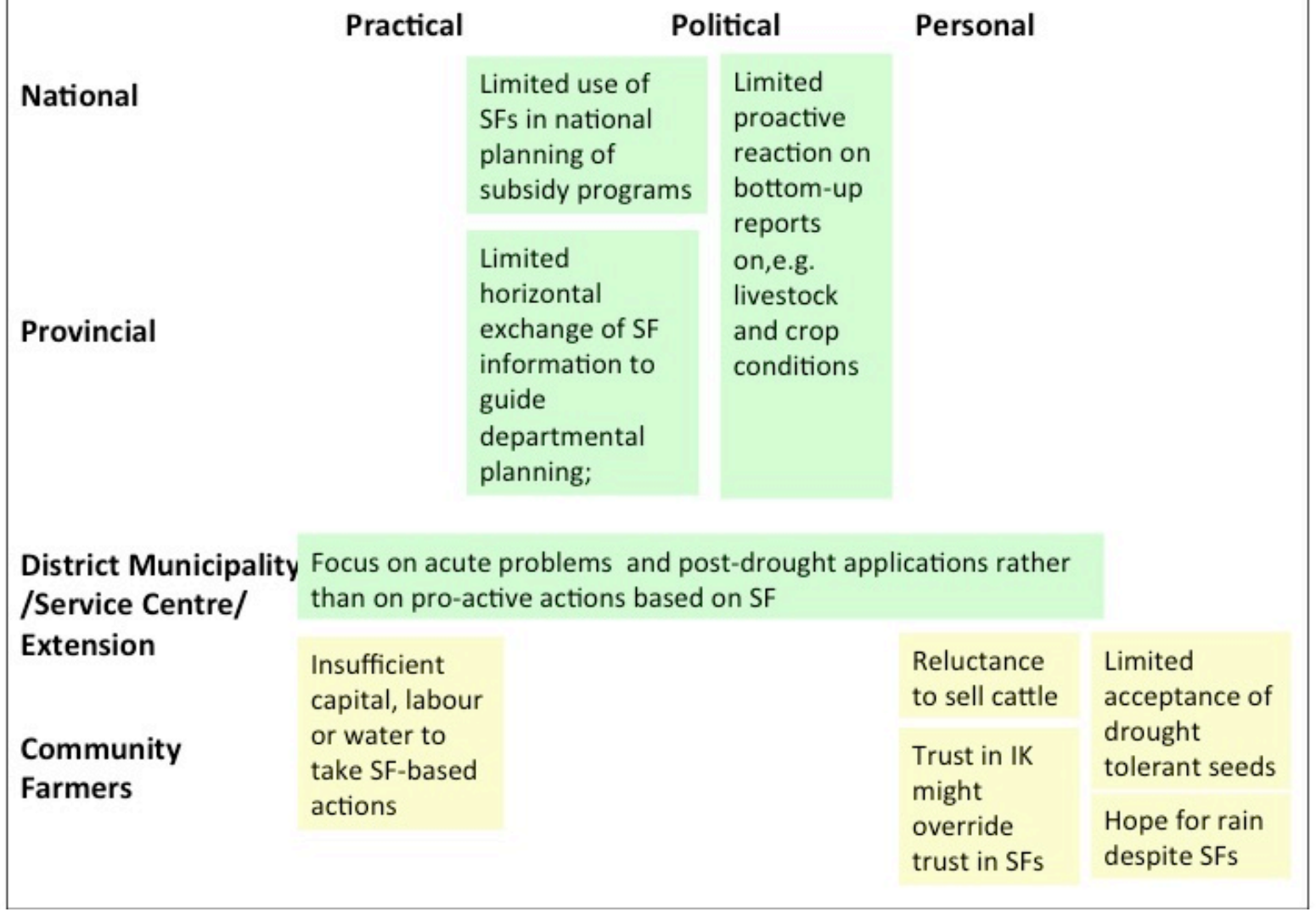

Figure 4. Barriers and limitations that inhibit politicians and policy-makers (green boxes) and farmers (yellow boxes) from taking actions based on seasonal forecast (SF) information at national, provincial, district municipality, service centre, and community levels. IK= indigenous knowledge

\subsection{Lack of use of SFs in national planning of subsidy programs}

Representatives of the provincial office said that SFs inform and influence the subsidy programs for smallholder farmers from the National Department of Agriculture yet extension officers did not perceive this to be the case based on the distributed subsidies in recent years. During our two-year field assessments, in the 2013-2014 season (forecasted as above-normal rainfall), free ploughing and drought-tolerant seeds and subsidized livestock fodder (in small quantities) were distributed in both Mokwakwaila and Lambani. In 20142015 (forecasted as below-normal rainfall), the same subsidies were provided at Mokwakwaila while at Lambani only subsidized livestock fodder was distributed.

\subsection{Limited horizontal exchange of information at the provincial level}


A provincial level informant remarked that Disaster Management Services staff have little communication with staff from Crop and Animal Production Services about SFs. SF

information is disseminated through the vertical communication chains, as described above, but not used sufficiently to guide and inform other provincial divisions in their planning and operational activities.

\subsection{Unclear information and responsibilities for suggested recommendations}

Extension officers indicated that they do not have the specialized competence and expertise, or want to take responsibility for recommendations to farmers based on SFs. One officer expressed that recommendations should come from the provincial level, preferably the Research Division or Crop and Animal Production Services, who hold the expertise.

Provincial level respondents stated that Crop and Animal Production Services do make SFinformed recommendations that are distributed to extension officers through the local municipalities for example through a crop calendar devised for the coming season. Other extension officers expressed that it is unclear where such recommendations come from, who makes them and if and how they relate to SFs.

\subsection{Focus on reactive disaster management}

The district municipality Disaster Management Coordinators expressed that their work focused more on reactive than proactive disaster management. Representatives from the provincial office pointed out that even when farmers receive SF information, they do not or cannot always react to it in a proactive manner. Hence Disaster Management Services are compelled to continue to focus on reactive management strategies to alleviate droughtrelated losses through relief programs. Relief, which is distributed if farmers are among those who have experienced the most severe losses in the province, commonly arrives many months after the losses have occurred. The distributed payment is barely enough to help farmers recover their agricultural systems to pre-hazard conditions.

\subsection{Trust in signs in nature}

Farmers have mixed views on the reliability of SFs. Some accept and trust information provided from the extension service, while others rely more on signs in nature such as the behaviour of animals and plants or the positions of the moon and stars to indicate coming 
weather conditions [29]. One farmer said that during the previous year, he had used these signs to guide his farming activities instead of following the advice of the extension officers but the local signs had been incorrect. Other farmers however do trust and use these signs to guide their farming activities such as the timing of planting.

\subsection{Hope for rain}

The SF information that extension officers disseminate to farmers can be communicated with or without a level of uncertainty in the forecasts. When a range of uncertainty was presented, the majority of farmers in the study area showed a preference to believe in above-normal forecasts [29]. In spite of forecasts predicting dry conditions, many farmers remain hopeful and still cultivate an area that would be suitable under normal rainfall conditions. A representative of the provincial Disaster Management Service stated, "Farmers always hope it will rain" despite what SFs or signs in nature may indicate and they act on this hope. Many farmers expressed that even when they see or hear signs that it will be a dry year, they still plant the maximum area of land and keep their livestock herds because they trust in God to send rain [29].

\subsection{Preference for indigenous seed varieties}

Although farmers plant drought-tolerant seeds (especially when they are distributed by government subsidy programs), some farmers pointed out that they are expensive because they cannot be stored so new seeds must be purchased each year. A few farmers said they do not like the taste and consistency of drought-tolerant maize varieties and instead prefer to plant indigenous seeds. Other farmers related that they have planted hybrid varieties yet they have not attained higher yields [29].

\subsection{Reluctance to downsize livestock numbers}

Livestock rearing and large herds are for many smallholder farmers in Limpopo part of local culture and important sources of income. Extension officers expressed that it is a major problem that farmers are reluctant to sell livestock and they often wait too long during dry periods to sell them, so that the livestock are very thin and fetch low prices if and when farmers eventually sell them. Younger people, living in urban areas also own cattle and their older relatives may be reluctant to sell them without the direct instructions from their 
owners and in some cases even watch them die in dry periods from lack of water and fodder.

\subsection{Insufficient resources}

While many smallholder farmers intend to undertake recommended strategies from extension officers, a large majority of farmers do not have the financial and physical resources to perform them. Their agricultural systems are supplemented by pensions and disaster relief (if they are fortunate enough to receive it after exceptionally dry periods) [29]. In other studies, farmers pointed out similar barriers inhibiting them from changing their farming practices in response to climate-related factors. In Limpopo, 33\% of farmers identified "no access to water" as hindering them from enforcing recommended adaptation measures to climate change ahead of $24 \%$ who said "lack of credit/savings" [33]. Another Limpopo study found that although smallholder farmers preferred to use hybrid seeds for increased yields, the majority could not because they lacked capital to purchase them [31]. In South Africa and Ethiopia, a third of the surveyed farmers pointed out lack of access to credit/money as the most significant barrier to implementing climate adaptation measures while the next largest group (8\%) pointed to a lack of access to water for irrigation [34].

\section{Opportunities for transformation}

In this section, we explore potential opportunities to make changes in the content, communication and use of SFs at different administrative levels, as well as among smallholder farmers across the practical, political and personal spheres.

\subsection{The practical sphere}

Technical problems including inconsistent Internet/Wi-Fi connections and unreliable access to LDARD email accounts are difficult to solve, as this responsibility lies outside the department's mandate. The recent move to allow SF information to be sent to private emailaccounts was a positive measure to increase the chances that the information is received in a timely manner.

With regard to the content and dissemination of SFs, most informants identified limitations that lie in the practical sphere (e.g., related to the design, content and dissemination of early warning system). Some respondents identified that the shortcomings 
in forecast content and format could be remedied with rather limited efforts e.g. providing maps at larger scales and finer spatial resolution.

At district municipality level, information could be collected in greater detail on emerging drought conditions by regular monitoring of suitable indicators and observations, and vegetation activity maps could be groundtruthed to validate, update and increase map accuracy. Efforts could also be focused to improve understanding of the probabilistic forecasts. Disaster Management Services at provincial level could investigate if officers at the district and service centre levels perceive the texts and illustrations in the provided forecasts as giving unclear or conflicting information, and if that is the case, disseminate a clearer message. The use of the terms, "virtually certain, very likely, likely", e.g. as in the IPCC AR4 technical summary report [35] might increase understanding. It has however been found that users often interpret these terms differently [36] so test of this or alternate wordings and of different types of visual information could be undertaken with different LDARD user groups to find the terminology and visual aids that enhance understanding.

Respondents had different perceptions about the extent to which Disaster Management Services collaborates with Crop and Animal Production Services to make site-specific recommendations based on SF information. While provincial representatives said that extension officers receive crop calendars based on specific SF recommendations from Crop and Animal Production Services, extension officers in both districts said that this was not the case. One officer said, although the crop calendar is received, it is only valid for normal weather conditions, not for excessively wet or dry years, which would suggest that it is not strongly influenced by SFs. Increased communication between the service centre and provincial level staff could enhance understanding of how animal and crop-related recommendations are created which in turn could lead to heightened acceptance, trust and dissemination of the information. The district municipality level of Disaster Management Services could provide an important two-way information hub to regularly communicate eventual misunderstandings or knowledge gaps between provincial and service centre levels.

Extension staff suggested creating district forums for the purpose of collectively discussing the latest SFs. This could ensure that extension staff has received the forecasts, facilitate correct interpretation of the forecasts and encourage timely dissemination to farmers. Site-specific recommendations from Animal and Crop Production Services could 
also be shared and discussed in this forum that would address the lack of clarity as addressed above. As the most important information for farmers is the planting date for maize, one meeting could be organized shortly after the release of the August-September forecast. District municipality level Disaster Management Services staff could be responsible for organizing this meeting. If resources allow, another forum meeting could be held in midseason (especially in dry years) so extension officers could report of any emerging droughtrelated conditions, which could be summarized by district municipality level staff and relayed to the provincial office.

Extension and Advisory Services at service centre level have an important role to help smallholder farmers enhance their agricultural productivity and engage in adaptation measures in the face of climate extremes. Besides their potential usefulness for smallholder farmers, SFs could also help extension officers to prepare for challenges that are most likely to arise during the coming season, e.g., crop failures and livestock diseases. This could aid in planning of interventions, information and activities to speed up processes in the same way as how SFs can be used to identify tasks that can be done in advance to quicken crisis response [20].

\subsection{The political sphere}

Our results support findings from other South African studies that have stressed the importance of politically addressing contextual vulnerability factors linked to poverty and access as part of drought risk management in order to increase farmers' resilience to the impacts of climate variability and change (e.g. [34] [37] [33] [38]. We interpret the political sphere as that which influences systems, institutions and structures. The top-down flow of SF information aims to ensure a uniform system of and access to SF information that becomes locally adapted as it moves through the defined chain of administrative levels. However, if roles, responsibilities and mandates are unclear, and time and resources are limited, there is a risk that SF information including recommendations on crop and animals management is not sufficiently site-specific to be useful or that those that receive it (both farmers and extension officers) do not trust it.

South Africa, through the provision of subsidies to smallholder farmers does to some degree aim to address the pre-conditions that underlie their vulnerability. Free ploughing, free drought-tolerant seeds and subsidized fodder can be seen as forms of preventative risk 
management, as they address underlying disaster risk drivers such as poverty and poor land management. Yet the level of subsidies although supporting smallholder farmers is not sufficient to enable them to fortify their farming systems and get consistently higher yields. Other types of targeted interventions would also be required such as investments in water infrastructure e.g. water harvesting to heighten farmers' resilience to future drought conditions [17]. There were divided perceptions between LDARD staff at provincial and service centre levels, as to if and to what degree SFs inform subsidies. In the two years of our study, one forecasted as wetter and one drier than normal, free ploughing and droughttolerant seeds and subsidised fodder (in very limited amounts) were distributed. Different drought-tolerant seed varieties were distributed each year which indicates that their selection may have be informed by SFs, yet the same amount of subsidized fodder was offered in both years. Free ploughing was part of a 5-year program, which indicates that not all subsidies are informed by SFs. The small amount of subsidized fodder might also indicate that the government does not intend to support livestock throughout the year but instead recommends downsizing herds if sufficient fodder cannot be obtained.

Although Disaster Management Services does disseminate SF information, a bulk of its work is still the assessment and coordination of disaster relief, which indicates a reactive, crisis management approach. Because many farmers are not able to respond to forecasts of hazardous events, relief schemes are still required to support those that have suffered extreme losses. However there do not appear policies in place that allow aid to be distributed even as extreme dry or wet conditions emerge and cause damage, rather only after the crisis has ended. Aid available even in earlier stages of an emerging crisis would indicate a stronger crisis management approach but this would require rapid assessments of hot spots, effective channels for bottom-up communication and targeted support. This is where SFs and the updated vegetative activity information at larger scales could potentially help by increasing the understanding of where and how quickly conditions are changing and the direction of the forecasted trend in the coming months. However disaster relief can only be distributed in exceptionally hazardous conditions. If climate conditions in South Africa become increasingly and consistently drier, other more comprehensive strategies and decisions, aside from free ploughing, seed subsidies and disaster relief, will be necessary to support smallholders and address poverty and food security issues. 
The different understandings between extension officers and provincial staff regarding if and how SF-based recommendations are made, indicates a lack of clarity about this process. This calls for clarifications of the roles that different provincial divisions have in making SFinformed recommendations about crop and animal management, who has responsibility for disseminating them to district and service centre levels and through which channels. Clearer communication platforms could increase dialogues and collaboration about SF information between Disaster Management Services, Crop and Livestock Production Services and Extension and Advisory Services divisions. As mentioned earlier, the district municipality level could coordinate communication between the provincial and service centre levels and signal if information is not being received and understood to minimize conflicting information or misunderstandings.

Besides changes to communication structures and systems, extension officers could be given a stronger role in preventative disaster management by allotting sufficient time in their duties to disseminate SF information, discuss recommendations with farmers and evaluate the outcomes of response actions. In the Eastern Cape and Free State provinces of South Africa, Extension Services were reluctant to disseminate early warnings, based on SFs, as they were not part of the Agricultural Disaster Management unit and thus not obligated to do so [39]. This is not the case in Limpopo but it indicates how institutional organization and clear assignment of duties and responsibilities influences the spread and use of SFs. High extension staff to farmer ratios places a heavy burden on Extension and Advisory Services aside from additional work in proactive disaster management. Although Limpopo Province in 2007 had the highest number of extension officers in the country, it still numbered as one of the four provinces in South Africa with the highest shortfall of extension personnel given the number of smallholder farmers. Resources that are invested in SFs will not likely give good returns if extension staff do not have sufficient time to receive, discuss and understand SF information, share it with farming communities and discuss and evaluate response outcomes.

\subsection{The personal sphere}

SFs and EWS are only useful if farmers can respond to the information and mitigate potential damages. Transformations in the personal sphere such as changed beliefs, values, worldviews and paradigms are a important part of this process and could be triggered by, 
e.g., increased awareness, knowledge and understanding about what SFs are and the potential benefits of responding to the information. In this section, we focus on individuals, both extension officers and farmers who have participated in this study, however, many barriers in the political sphere are also due to the mind-sets of politicians and administrators at different levels that influence how subsidies and relief aid are distributed and longer term development goals and the future of smallholder agriculture.

It can be difficult for many older farmers above pension age, the majority of the smallholder farmers in our study communities, to trust SF information especially if it conflicts with signs in nature that many are accustomed to using. Simple explanations of how SF information is created and discussions of SF information together with observed signs in nature can be ways to increase understanding and trust of SFs [29]. The current dominance of older farmers among smallholders also means that they might not always have the capacity to act on recommended actions, not only because of their beliefs, but also due to practical reasons. Women make up 70-80\% of farmers in Limpopo [40], which can also make activities requiring heavy physical labour such as mulching and making drainage channels more difficult, and might require hiring labour, and as holders of the main responsibilities for most household duties and care of families, their time can be limited by other duties. It may also take time for farmers to trust in SFs and follow related recommendations to counter-act the strong hope that many have for timely and sufficient rains. This hope deters them from selling their livestock and reducing the amount of land they sow in years where signs or forecasts indicate excessively dry conditions. Subsidies such as free ploughing and seeds can also been perceived as counter-acting the use of SF information by farmers in dry years, as there is no incentive for them to cultivate smaller areas (saving labour for planting, weeding and harvesting). The potential for using SF information is likely to be higher for emerging farmers, who have an increased capacity to access resources and technical training and knowledge.

Local values about cattle rearing might also lead to reluctance among farmers to follow advice about the downsizing of herds. Extension officers pointed out that although some farmers have begun to manage their herd sizes more dynamically according to environmental conditions and SF information, others show little tendency to change their practices because livestock are a strong symbol of assets. The officers suggested that if some farming champions follow SF informed advice and their strategies are proven successful, 
others might follow. Yet where farmers have followed SF recommendations and they have proved inaccurate, the results might rather make others even more reluctant to use forecast information. When media exaggerated a warm El Nino event, some Zimbabwean smallholders reduced their cropped areas and their yields were reduced. The forecasts were criticized and reliance on future forecasts was decreased [41]. Although SF information needs to be relayed in a simple manner to increase understanding, it is most important that it is clear that forecasts are informed predictions that are more or less likely to occur but not with definite certainty.

The smallholder farmers that participated in this study have little to no buffers in terms of economic resources so even one disastrous year in agriculture has profound consequences. This can make them reluctant to take any risks with their agricultural activities even if they have access to credit to undertake response measures to SF information e.g. applying fertilizers when soil moisture is high or providing nutritional mineral blocks for livestock. Personal change to accept and trust new types of information can be slow but evaluation of SF informed field trials undertaken together with community champions, especially women, can contribute to the evaluation and increased understanding of potential benefits of using SF information.

Long-term visions for agriculture in South Africa by decision-makers and planners need to recognize and support the current and future role of smallholder agriculture in global food security and efficient use of land and resources. Positive transformation would involve the evaluation and adjustment of the mind-set of decision-makers and planners to coordinate initiatives that support smallholders but also find ways to contribute to their socio-economic development and food, nutrition, water and environmental security with a minimum of negative trade-offs. This would involve a more strategic use of SFs and EWS for risk management but also an exploration of other means to decrease vulnerability and enhance rural livelihoods e.g. investments to construct or support water infrastructure, rainwater harvesting, organic, low-carbon or small-scale commercial agriculture, livelihood diversification with off-farm activities. Such changes would however require access to markets, skills and finance. Integrated strategies need to be developed that can transform smallholders' subsistence agriculture and dependence on subsidies and relief aid to agricultural systems with good and steady returns that allow them to live well but also fulfill larger food security goals. 


\section{Conclusions}

For SF information to more significantly play a role in the transition from disaster to risk management among government authorities and smallholder farmers in Limpopo, a number of measures would need to be addressed in the practical, political and personal areas to enable the increased use of SF information by farmers. Practical changes can be more easily rectified such as improvements in SF form and content and improvements to the top-down dissemination at LDARD. These however will have little effect without comprehensive changes to the political i.e. systems and structures including the increased used of SF information in crop and animal management and well-informed and timed support and subsidies measures and in the personal sphere e.g. acceptance and trust in SF information that results in changed behaviour of smallholders that minimizes their losses and increases their resilience.

Polices that support and regulate subsidies and disaster relief could hold a more proactive approach. While South Africa already does, more than other African nations, provide subsidies to smallholder farmers, these could more closely be aligned with SFs so subsidies are available at the onset of the rainy season e.g. ploughing and seeds and appropriate to the forecasted conditions. Policy changes could make the collection and bottom-up dissemination of information about emerging drought conditions from ground observations and monitoring to higher administrative levels mandatory and include directives that guide the integration of the information with the latest forecasts. Early and more precise signs and locations of emerging conditions within the province could then inform proactive actions such as support distributed at the outbreak of or during extreme dry periods. Smallholder farmers could them minimize damages at an earlier stage. Increased horizontal communication platforms between provincial divisions could enable forecast information to better inform their activities and areas of responsibility, e.g., Crop and Animal Services could make and clearly communicate appropriate site-specific recommendations that are disseminated and discussed with Extension and Advisory Services staff at district municipality and service centre levels. Increased clarity about the responsibilities and assignments related to the dissemination of SF-informed recommendations at all levels of LDARD could minimize misunderstandings and increase trust in SF-based information by extension staff. 
The mind-sets of farmers but also politicians and policy makers could be shifted to a greater risk management focus. Farmers may not be acting in response to SF information because they do not choose to (downsize livestock herds) or cannot (afford needed interventions e.g. drought-tolerant seeds or fertilizers or hire additional labour for e.g. mulching). Site-specific SF-informed recommendations and regular field trials could increase their understanding of the potential benefits of using SFs and trigger alternative strategies and values in animal husbandry and cultivated agriculture. Politicians and decision-makers need to make long-term goals for South African agriculture and design relevant subsidy programs that help smallholder farmers build agricultural systems that adequately sustain their families but also address food security and efficient land use and management challenges.

\section{Acknowledgements}

We gratefully acknowledge the participation and help from community members of Lambani and Mokwakwaila, LDARD staff from provincial to service centre level and all workshop participants from other organizations. We also thank the Swedish International Development Agency (SIDA) for funding project SWE-2011-164.

\section{References}

[1] IPCC, Climate Change 2014: Impacts, Adaptation, and Vulnerability. Part B: Regional Aspects. Contribution of Working Group II to the Fifth Assessment Report of the Intergovernmental Panel on Climate Change, V.R. Barros, C.B. Field, D.J. Dokken, M.D. Mastrandrea, K.J. Mach, T.E. Bilir, M. Chatterjee, K.L. Ebi, Y.O. Estrada, R.C. Genova, B. Girma, E.S. Kissel, A.N. Levy, S. MacCracken, P.R. Mastrandrea, and L.L. White (Eds.), Cambridge University Press, Cambridge, United Kingdom and New York, NY, USA, 2014.

[2] O. Rojas, A. Vrieling, F. Rembold, Assessing drought probability for agricultural areas in Africa with coarse resolution remote sensing imagery, Remote Sens. Environ. 115(2) (2011) 343-352.

[3] T. Raney, G. Anríquez, A. Croppenstedt, S. Gerosa, S. Lowder, I. Matuscke, J. Skoet, The role of women in agriculture, ESA Working Papers, 11-02, FAO, Rome, 2011. 
[4] S. Asfaw, G. Maggio, Gender integration into climate-smart agriculture - Tools for data collection and analysis. Economics and Policy Innovations for Climate-Smart Agriculture (EPIC), January 2016 FAO, Rome, 2016.

[5] S.E. Park, N.A. Marshall, E. Jakku, A.M. Dowd, S.M. Howden, E. Mendham, A. Fleming, Informing adaptation responses to climate change through theories of transformation, Glob. Environ. Chang. 22(1) (2012) 115-126.

[6] IPCC, Climate Change 2014: Impacts, Adaptation, and Vulnerability. Part A: Global and Sectoral Aspects. Contribution of Working Group II to the Fifth Assessment Report of the Intergovernmental Panel on Climate Change, C.B. Field, V.R. Barros, D.J. Dokken, K.J. Mach, M.D. Mastrandrea, T.E. Bilir, M. Chatterjee, K.L. Ebi, Y.O. Estrada, R.C. Genova, B. Girma, E.S. Kissel, A.N. Levy, S. MacCracken, P.R. Mastrandrea, L.L. White (Eds.), Cambridge University Press, Cambridge, United Kingdom and New York, NY, USA, 2014.

[7] M. Pelling, Adaptation to climate change: from resilience to transformation, Routledge, London and New York, 2011.

[8] K. O’Brien, S. Eriksen, T.H. Inderberg, L. Sygna, Climate Change and development: adaptation through transformation, in: T.H. Inderberg, S. Eriksen, K. O’Brien, L. Sygna (Eds.), Climate Change Adaptation and Development - Transforming Paradigms and Practices, Routledge, London and New York, 2015, pp. 273-289.

[9] N.S. Brooks, J. Anderson, I. Ayers, I. Burton, I. Tellam, Tracking adaptation and measuring development. London: IIED, 2011.

[10] S. Borron, Building resilience for an unpredictable future: how organic agriculture can help farmers adapt to climate change, FAO, Rome, 2006.

[11] L. Rickards, S.M. Howden, Transformational adaptation: agriculture and climate change. Crop and Pasture Sci. 63 (2012) 240-250.

[12] D.A. Wilhite, M.V.K. Sivakumar, R. Pulwarty, Managing drought risk in a changing climate: The role of national drought policy, Weather and Clim. Extremes 3 (2014) 413.

[13] UNISDR, Sendai Framework for Disaster Risk Reduction, United Nations International Strategy for Disaster Reduction, Geneva, Switzerland, 2015.

[14] GWP, Global Water Partnership, Guidelines for preparation of Drought Management Plans, Development and implementation in the context of the EU Water Framework Directive. GWP, Eastern Europe, 2015. 
[15] D.A. Wilhite, M.J. Hayes, C. Knutson, K.H. Smith, Planning for drought: Moving from crisis to risk management. J. Amer. Water Res. Assoc. 36(4) (2000) 697-710.

[16] R. Hassan, Drought management strategies in South Africa and the potential for economic policy instruments. In K. Schwabe, J. Albiac-Murillo, J.D Connor, R. Hassan, L.M. González (Eds.), Drought in arid and semi-arid regions: a multi-disciplinary and cross-country perspective. Springer Sci. Bus. Media, 2013.

[17] M.J. Ngaka, Drought preparedness, impact and response: a case of the Eastern Cape and Free State provinces of South Africa, Jamba, J. Dis. Risk Studies $4(1)$ (2012), 36-45.

[18] D. A. Wilhite, C. L. Knutson, Drought management planning: Conditions for success." Options Mediterraneennes Series A 80 (2008) 141-148.

[19] Y.T. Bahta, A. Jordaan, F. Muyambo, Communal Farmers' perception of drought in South Africa: policy implication for drought risk reduction. Intl. J. Dis. Risk Red. (2016). doi:10.1016/j.ijdrr.2016.10.007.

[20] R. Bailey, R. Managing famine risk: linking early warning to early action, Chatham House, London, 2013.

[21] M.C. Lemos, T.J. Finan, R.W. Fox, D.R. Nelson, J. Tucker, The use of seasonal climate forecasting in policymaking: lessons from Northeast Brazil. Clim. Chang. 55 (2002) 479-501.

[22] R.S. Pulwarty, T.S. Melis, Climate extremes and adaptive management on the Colorado River: lessons from the 1997-1998 ENSO event. J. Environ. Manage. 63(3) (2001) 307-324.

[23] R.S. Pulwarthy, M.V.K. Sivakumar, Information systems in a changing climate: Early warnings and drought risk management, Weather and Clim. Extremes 3 (2014) 14-21.

[24] S.J. Vermeulen, P.K. Aggarwal, A. Ainslie, C. Angelone, B.M. Campbell, A.J. Challinor, Lau C, Options for support to agriculture and food security under climate change, Environ. Sci. Policy, 15(1) (2012) 136-144.

[25] A. Patt, P. Suarez, C. Gwata, C. 2005. Effects of seasonal climate forecasts and participatory workshops among subsistence farmers in Zimbabwe, Proc. Nat. Acad. Sci U.S.A, 102(35) (2005) 12623-12628.

[26] J.W. Hansen, Integrating seasonal climate prediction and agricultural models for insights into agricultural practice Phil. Trans. R. Soc. B. 360 (2005) 2037-2047. 
[27] J.W. Hansen, S.J. Mason, L. Sun, A. Tall, Review of seasonal climate forecasting for agriculture in sub-Saharan Africa. Exper. Agric. 47(2) (2011) 205-240.

[28] K. O’Brien, C. Vogel, Coping with climate variability: the use of seasonal climate forecasts in southern Africa, Ashgate, Aldershot, U.K, 2003.

[29] L. Andersson, J. Wilk, P. Graham, J.J. Wikner, S. Mokwatlo, B. Petja, Drought Early Warning Detection - can it increase community resilience? Manuscript.

[30] Food and Agriculture Organisation (FAO), Drought impact mitigation and prevention in the Limpopo River Basin: a situation analysis, Land and Water Discussion Paper, FAO, Rome, 2004.

[31] S. Mpandeli, S. Evaluation of crop production practices by farmers in Tshakhuma, Tshiombo and Rabali Areas in Limpopo Province of South Africa, J. Agric. Sci. 6(8) (2014) 10-18.

[32] StatsSA (Statistics South Africa) Statistics by place, (http://www.statssa.gov.za) (accessed 28.07.16), 2011.

[33] G.A. Gbetibouo, Understanding farmers' perceptions and adaptations to climate change and variability: the case of the Limpopo Basin, South Africa. Intl. Food Policy Res. Inst. Discussion Paper 849 (2009).

[34] E. Bryan, T.T. Deressa, G.A. Gbetibouo, C. Ringler, Adaptation to climate change in Ethiopia and South Africa: options and constraints. Environ. Sci. Policy, 12(4) (2009) 413-426.

[35] IPCC, Summary for Policymakers. In: T.F. Stocker, D. Qin, G.-K. Plattner, M. Tignor, S. K. Allen, J. Boschung, A. Nauels, Y. Xia, V. Bex and P.M. Midgley (Eds.), Climate Change 2013: The Physical Science Basis. Contribution of Working Group I to the Fifth Assessment Report of the Intergovernmental Panel on Climate Change Cambridge University Press, Cambridge, United Kingdom and New York, NY, USA, 2013.

[36] National Research Council. Completing the Forecast: Characterizing and Communicating Uncertainty for Better Decisions Using Weather and Climate Forecasts. The National Academies Press, Washington, DC, 2006.

[37] K.D. Mutabazi, S. Sieber, C. Maeda, K. Tscherning, Assessing the determinants of poverty and vulnerability of smallholder farmers in a changing climate: the case of Morogoro region, Tanzania. Region. Environ. Chang. 15(7) (2015) 1243-1258. 
[38] C.S. Bahinipati, L. Venkatachalam, What drives farmers to adopt farm-level adaptation practices to climate extremes: empirical evidence from Odisha, India. Intl. J. Dis. Risk Red. 14 (2015) 347-356.

[39] F. Liedenberg, Agricultural Advisory Services in South Africa Discussion Paper. University of Pretoria.

(http://www.up.ac.za/media/shared/108/2015\%20Working\%20papers/agric advisory_services.zp64017.pdf) (accessed 17.05.16), 2015.

[40] Department of Agriculture, Forestry and Fisheries (DAFF), (http://www.daff.gov.za/doaDev/sideMenu/links/Digest3.htm\#NORTHERN\%20 PROVINCE) (accessed 17.06.17), 2005.

[41] A. Patt, Understanding uncertainty: forecasting seasonal climate for farmers in Zimbabwe, Risk Decision Policy, 6(2) (2001) 105-119. 